\title{
Interdisciplinaridade: um diálogo da língua inglesa moderna com a educação integral através de oficinas pedagógicas
}

\author{
Mercês P. Cunha Mendonça* \\ Iolene Mesquita Lobato ** \\ José Renato de Sousa Pereira***
}

\section{Resumo}

O objetivo deste trabalho é contribuir com a discussão em torno da noção de interdisciplinaridade na escola de tempo integral dialogando com a realidade da Língua Inglesa na prática cotidiana, a partir de um projeto educacional desenvolvido na Escola Estadual de Tempo Integral em Águas Lindas, GO. Essa ação articulou a prática pedagógica à realidade, assim como às habilidades e vivências dos educandos e sua proximidade com a língua inglesa, ou seja, trabalhou estrangeirismos (como nas palavras: hot dog, fast food, shopping, shorts, lan house, internet, Messenger, Facebook, dentre outras) encontrados em placas, rótulos, produtos, marcas comerciais, os quais contribuem no processo de ensino e aprendizagem. Assim, o artigo tratará de uma proposta sobre a importância da interdisciplinaridade na formaçáo do sujeito.

Palavras-chave: estrangeirismo, língua inglesa, educação integral e integrada.

\section{Interdisciplinarity: a dialogue between modern English and fulltime education} through educational workshops
Abstract
This study sets out to contribute to the discussion on the notion of interdisciplinarity in fulltime schooling by dealing with the reality of English in day-to-day practice, based on an educational project undertaken by the fulltime State School in Águas Lindas, Goiás. This project linked pedagogical practice to reality and the skills and experiences of students and their familiarity with the English language, that is, through loanwords such as hot dog, fast food, shopping, shorts, cyber café, Internet, Messenger, Facebook and others found in billboards, labels, products, trademarks, which could be used to contribute towards teaching and learning. Thus, the article deals with a proposal for the importance of interdisciplinarity in the formation of the subject.
Keywords: loanwords, English language, fulltime and integrated education.

\footnotetext{
* Professora do Centro de Ensino e Pesquisa Aplicada à Educaçáo Cepae/UFG. E-mail: mercesmendonca@yahoo.com.br

** Coordenadora de Tutoria do Curso de Extensão em Educação Integral e Integrada Cepae/UFG/ SEB. E-mail: iolenelobato@gmail.com

*** Tutor a distância do Curso de Extensão em Educação Integral e Integrada Cepae/UFG/SEB. E-mail: professorjoserenato@hotmail.com
} 


\section{Introdução}

A educação integral é inseparável da vida, da cultura e da arte. É uma educação que estabelece a interaçáo entre as práticas cotidianas, espaços e tempos da escola e da comunidade (PADILHA, 2012). Por possibilitar essa educação completa, inteira, integral, que passa pelos direitos humanos e a cidadania, faz-se necessário considerar e utilizar as habilidades e vivências que as crianças e adolescentes trazem ao chegarem à escola. Poderíamos enumerar um leque delas oriundas de distintas experiências; todavia, nosso recorte focalizará aquelas provenientes da língua inglesa, através de palavras como hot dog, fast food, shopping, shorts, lan house, Orkut, Messenger, internet, Facebook e outras, encontradas em placas, rótulos, produtos, marcas comerciais, presentes no cotidiano do referido público.

O professor integral deve considerar em seu planejamento o conhecimento que seus alunos têm sobre a língua inglesa e articulá-lo nas atividades e/ou oficinas que venham a desenvolver na escola. Vale mencionar que trabalhar com os estrangeirismos em campo, baseado em registros escritos nas paredes de supermercados, lojas, propagandas em painéis de rua, produtos utilizados em casa, dentre outros ambientes, permite ao aluno perceber a relevância do estudo da língua estrangeira, como parte de sua realidade sociocultural, contribuindo, dessa forma, para o processo de ensino e aprendizagem.

É importante entendermos que a língua inglesa, mesmo sendo considerada a língua de maior amplitude, divulgação e reconhecimento mundial, foi inserida na cultura do Brasil apenas na década de 1940, logo após a Segunda Guerra Mundial, como afirma Moura:

O Brasil foi literalmente invadido por missóes de boa vontade americanas, compostas de professores universitários, jornalistas, publicitários, artistas, militares, cientistas, diplomatas, empresários etc. - todos empenhados em estreitar os laços de cooperação com brasileiros - além das múltiplas iniciativas oficiais. (1988, p. 33)

Com a Lei de Diretrizes e Bases (LDB), em 1961, estabelece-se a obrigatoriedade, apenas de forma parcial, de inserção da Língua Estrangeira no $1^{\circ}$ grau (Brasil, 1961). Em 1971, com a redução do ensino de 12 para 11 anos, algumas escolas públicas retiram a Língua Estrangeira do $1^{\circ}$ grau e, no $2^{\circ}$, a carga horária se limita a apenas uma hora semanal, como fundamenta Leffa (1999, p. 13-14): 
A redução de um ano de escolaridade e a necessidade de se introduzir a habilitação profissional provocaram uma redução drástica nas horas de ensino de língua estrangeira, agravada ainda por um parecer posterior do Conselho Federal de que a língua estrangeira seria "dada por acréscimo" dentro das condiçóes de cada estabelecimento. Muitas escolas tiraram a língua estrangeira do primeiro grau, e no segundo grau não ofereciam mais do que uma hora por semana, às vezes durante apenas um ano. Inúmeros alunos, principalmente do supletivo, passaram pelo $1^{\circ}$ e $2^{\circ}$ graus, sem nunca terem visto uma língua estrangeira.

Em 1996, com a mudança da nomenclatura - $1^{\circ}$ e $2^{\circ}$ graus por Ensino Fundamental e Médio -, a LDB deixa clara a necessidade de uma Língua Estrangeira nos dois ciclos (1996), ficando a escolha a cargo da comunidade escolar. Acrescenta-se, então, no Ensino Médio, a possibilidade de uma segunda Língua Estrangeira, de acordo com a instituição.

Mesmo com as dificuldades de implantação e sistematização da língua inglesa nas escolas brasileiras, a mesma deve ser contemplada, trabalhada em sala de aula, por ser importante na formação do aluno. Assim, a escola de tempo integral deve articular açóes e projetos que permitam a interdisciplinaridade entre a Língua Inglesa e outras disciplinas e/ou oficinas, oferecendo ao educando uma aprendizagem significativa.

\section{A proposta}

No currículo de muitas escolas, existiam diversas áreas, funcionando como "ilhas" no processo de ensino e aprendizagem, o que trazia dificuldade para os educadores interligarem os diversos campos do conhecimento, fato que separava a escola do dia a dia de convivência dos alunos.

Nesse modelo, o aluno perdia muito, pois não entendia a relação intrínseca entre as disciplinas, além de não compreenderem a integração entres os diversos campos, como a matemática e a história, por exemplo. Essa proximidade só foi percebida pela comunidade escolar em meados dos anos 1960 e inserida, de fato e em lei, na elaboração da Lei de Diretrizes e Bases da Educação (LDB, 1996). Essa temática vem tomando espaço nas escolas brasileiras e tem sido discutida entre alguns estudiosos da área como Japiassú (1976), Jantsch e Bianchetti (1997), Demo (1998) e Moll (2012).

Segundo Japiassú (1976), para haver interdisciplinaridade faz-se mister a intercomunicação entre as disciplinas, de modo que resulte uma 
modificação entre elas, através de diálogo compreensível, uma vez que a simples troca de informaçóes entre organizaçóes disciplinares não constitui um método interdisciplinar.

$\mathrm{O}$ autor indica dois níveis de trabalho interdisciplinar. O nível pluridisciplinar que consiste no estudo do mesmo objeto por diferentes disciplinas, sem que haja convergência quanto aos conceitos e métodos; e o interdisciplinar que proporciona uma integração das disciplinas no nível de conceitos e métodos. A unidade do objeto não se dá de forma a priori nem a posteriori, pois o objeto real náo pode ser apreendido como uma máquina que se pode manipular; tampouco é possível depreendê-lo pela organização dos dados, a partir da investigação científica. Para dar conta do interdisciplinar, o autor aponta dois métodos distintos e complementares: o método da tarefa, que se orienta para os empreendimentos humanos e da história, e que se aplica à procura de um objeto comum aos vários conhecimentos, culminando com a prática; e o método da reflexão interdisciplinar, que faz menção à reflexão sobre os saberes já constituídos e cujo objetivo é estabelecer juízo e discernimento.

Neste sentido, Demo (1998, p. 88) trabalha com a visão de que a interdisciplinaridade quer "horizontalizar a verticalização, para que a visão complexa seja também profunda, e verticalizar a horizontalização, para que a visão profunda seja também complexa”. E define a interdisciplinaridade "como a arte do aprofundamento com sentido de abrangência, para dar conta, ao mesmo tempo, da particularidade e da complexidade do real" (p. $88-89$ ). Ele sugere a prática da pesquisa em grupo como a metodologia mais indicada, pela possibilidade da cooperação qualitativa entre especialistas. Esta prática seria viabilizada através das equipes de profissionais ou pesquisadores especialistas, mediados pela linguagem, pelo diálogo e pelos métodos acessíveis a todos.

Desse modo, na interdisciplinaridade uma disciplina deixa de ser principal no cenário escolar. Liga-se às demais (ou a outras) e focaliza o aprendizado de forma que o aluno entenda a relaçấo simples entre os diversos campos do saber. Podemos exemplificar mencionando a Língua Inglesa Moderna e a História, que se fundem, proporcionando ao aluno uma gama de oportunidades essencial à imersão do conhecimento, não individualizado mas, sim, integrado com as realidades que o norteiam.

Mesmo sabedores dessa proximidade entre as áreas, da importância da interdisciplinaridade, muitos educadores ainda resistem em dialogar 
com outros saberes. Para mudar essa realidade propôs-se a realizaçáo de um Projeto na Escola Estadual de Tempo Integral, localizada em Águas Lindas de Goiás, GO. O objetivo foi instigar os docentes a praticar diariamente o diálogo da Língua Inglesa com outra disciplina através de oficinas planejadas, organizadas e articuladas, objetivando uma aprendizagem significativa, coerente e coesa.

Após apoio do grupo gestor, nos reunimos com o grupo de professores, num total de quinze. Apresentamos nosso projeto e marcamos algumas reunióes para sistematizar as açóes. Grande parte se sensibilizou com a proposta e mostrou interesse, enfatizando que buscam colocar em prática a interdisciplinaridade, mas que encontram dificuldade em realizá-la.

Nossa proposta foi articular o conhecimento prévio dos alunos, no que se refere ao estrangeirismo, às disciplinas de Português e Arte, elaborando, posteriormente, as oficinas de música e dança. Antes de colocar em prática o projeto, contextualizamos a interdisciplinaridade e estudamos alguns autores, como Anísio Teixeira (1959) e Darcy Ribeiro (1986), idealizadores da educação integral. Depois de algumas semanas de planejamento, estudos e reflexóes acerca dos procedimentos e açóes, iniciamos um diálogo com os alunos.

Com um total de trinta alunos, começamos a mapear, por meio de um questionário, as palavras em inglês que eles conheciam. Dentre as mais faladas, foram destacadas: "internet", "Messenger", "Orkut", "fast food", "lan house", "Facebook", "mouse", "outdoor". A partir desse conhecimento prévio foram apresentadas discussóes acerca do tema, assim como um estudo introdutório da inserção dos estrangeirismos no Brasil. A realidade social, o contexto histórico e a relevância da língua em debate na nossa cultura também foram apresentados e discutidos. Nossa primeira ação foi direcionar os discentes a localizar em suas próprias residências, assim como em lojas (produtos), placas, músicas, em todos os ambientes possíveis, os estrangeirismos encontrados. Eles deveriam ser anotados, reforçando assim o que era aprendido em sala de aula com exemplos práticos.

Os resultados foram os mais diversos: os alunos perceberam o quanto a língua estrangeira em estudo está presente no nosso cotidiano: em embalagens de mercadorias, propagandas, nomes de colegas e conhecidos, nomes de praças e ruas; enfim, essa vivência contribuiu e facilitou a sequência para a próxima etapa da oficina. 
Nessa etapa a ação consistiu na montagem de um painel com todas as palavras encontradas pelos alunos. Os professores de Inglês e Português trabalharam juntos conceitos de ambas as línguas, partindo da realidade dos alunos e enfatizando como o Inglês, dentro de um contexto histórico, influenciou nossa cultura e língua materna.

Nesse contexto, os alunos aprenderam sobre a relevância da comunicação nos diversos contextos. Adentraram nos níveis de linguagem, nas semelhanças e diferenças com o idioma tema deste trabalho, nas relações históricas entre ambos, e no que é divulgado pela mídia em ambientes virtuais.

Paralelamente, pesquisaram o percurso histórico das duas línguas, o que, por sinal, fora introduzido pelos docentes como incentivo a posterior pesquisa a ser realizada pelo grupo. Foram realizadas entrevistas com idosos e primeiros habitantes da cidade de Águas Lindas de Goiás para compreenderem a origem e formação das pessoas que construíram a cultura da língua no ambiente em que hoje residem.

Com o trabalho de promoção do saber a partir de conhecimentos distintos e ao mesmo tempo relacionados, diante da temática, os alunos partiram para a aula prática. Os professores pediram aos alunos que registrassem todos os exemplos concretos encontrados sobre o tema, para apresentarem, em exposição, à própria comunidade. Dessa forma, realizaram a construçáo do saber a partir do meio em que vivem, aprendendo, além disso, a observar a construção do conhecimento em seu próprio espaço. Entendemos, dessa forma, que

o professor náo pode esquecer que o aluno aprendeu muita coisa antes de entrar para a escola e que continua aprendendo muita coisa fora da escola. Portanto, o que o professor ensina não é a única influência que o aluno recebe nem a mais importante. Fora da escola, ele aprende muita coisa importante para sua própria aprendizagem na escola, importante para a formaçáo da sua personalidade, importante para toda a sua vida etc. (PILETTI, 1997, p. 59)

A partir da exposiçáo desse autor, percebemos que as experiências educacionais são advindas da família, de forma proporcional e natural, e também de outros ambientes sociais fora da escola. Dessa forma, a concepção de educação como hominização, para o autor, é de que o homem é um ser inacabado, que se constrói enquanto ser humano, social e singular. A concepção de educação é vista, assim, como a apropriação individual do 
sujeito que precisa se permitir aprender. Ademais, esta relação é por natureza social, na medida em que pressupõe a mediação do outro.

Após visitarem supermercados, lojas, analisarem placas de propagandas (outdoors), anúncios e palavras utilizadas em objetos do nosso cotidiano, foram elaborados painéis para exposição ao público. Diante de todos os registros foram selecionados os com melhor qualidade, impacto na realidade da comunidade e frequência de uso. A professora de Arte, que teve papel essencial no desenvolvimento desta etapa da oficina, apresentou modelos de painéis aos alunos e eles tiveram a liberdade de escolher o modelo que apresentasse melhor visualização para a aprendizagem do público. A partir da construçáo dos expositores foram organizados grupos que seriam divididos com o intuito de haver material exposto para apresentação de toda a classe.

Em data marcada para abertura da oficina, os visitantes puderam contemplar uma realidade próxima ao seu dia a dia. Foram explicados passo a passo a construçáo do trabalho, inclusive como os alunos chegaram a esta temática e sua relevância para nossa sociedade. Produtos que continham texto em Língua Inglesa e que não eram percebidos por muitos foram expostos. A oficina foi marcada por um coral produzido pelos próprios alunos, apresentando a força da música internacional em nossos dias, inclusive em novelas e filmes.

Durante esse projeto, percebemos que, de certa forma, nossa prática pedagógica tem consistido em aulas que direcionam o aprendiz a memorizar, decorar, talvez, porque isso dê menos trabalho. Todavia, no âmbito da educação integral faz-se necessário que o professor instigue e promova a aprendizagem significativa, capaz de promover mudanças e de somar na vida de seus alunos. É essencial a mudança em nossas práticas docentes não só no que se refere ao "quê ensinar", mas principalmente, ao "como ensinar". A educação integral nos proporciona uma grande amplitude diante destes questionamentos, pois nos apresenta uma realidade não vivida, mas que, por ser essencial, deve ser inserida em nosso meio profissional.

\section{Consideraçóes finais}

Jantsch e Bianchetti (1997) argumentam que a interdisciplinaridade não pode ser concebida fora dos modos de produção históricos em vigor. Isso significa que é produto de um processo que foi engendrado num contexto de construção do conhecimento ao qual subjazem a filosofia e a 
ciência. A abordagem interdisciplinar deve ser entendida como produto histórico. Tal compreensão não exclui a necessidade de avançar na direção de outro paradigma que permita uma aproximaçáo maior da visão histórica. Não implica também que interdisciplinaridade e especialidade não possam conviver de forma harmoniosa.

Concluímos, a partir do trabalho aqui apresentado, que o trabalho interdisciplinar promove uma compreensão do ser humano de forma dialética, desenvolvendo-se na medida em que desbrava as fronteiras da filosofia do sujeito.

\section{Referências}

BRASIL. Ministério da Educação e Cultura. Lei de Diretrizes e Bases da Educação Nacional. Brasília: Ministério da Educação e Cultura, 1961.

BRASIL. Ministério da Educação e Cultura. Lei n. 9.394, de 23 de dezembro de 1996. Fixa as Diretrizes e Bases da Educação Nacional. Brasília: Ministério da Educação e Cultura, 1996.

DEMO, P. Conhecimento moderno: sobre ética e intervenção do conhecimento. Petrópolis: Vozes, 1998.

JANTSCH, A. P.; BIANCHETTI, L. Interdisciplinaridade: para além da filosofia do sujeito. Petrópolis: Vozes, 1997.

JAPIASSU, H. Interdisciplinaridade e patologia do saber. Rio de Janeiro: Imago, 1976.

LEFFA, V. J. O ensino de LE no contexto nacional. Contexturas, APLIESP, n. 4, p. 13-24, 1999.

MOURA, G. Tio Sam chega ao Brasil: a penetração cultural americana. São Paulo: Brasiliense, 1988.

MOLL, J. A agenda da educação integral: compromissos para sua consolidação como política pública. In: MOLL, J. (Org.). Caminhos da educação integral no Brasil: direito a outros tempos e espaços educativos. Porto Alegre: Penso, 2012. p. 129-146.

PADILHA, P. R. Educação integral e currículo intertranscultural. In: MOLL, J. (Org.). Caminhos da educação integral no Brasil: direito a outros tempos e espaços educativos. Porto Alegre: Penso, 2012. p. 189-206. 
PILETTI, N. Psicologia educacional. São Paulo: Ática, 1997.

RIBEIRO, D. O livro dos CIEPs. Rio de Janeiro: Bloch, 1986.

TEIXEIRA, A. Centro educacional Carneiro Ribeiro. Revista Brasileira de estudos Pedagógicos. Rio de Janeiro, v. 31, n. 73, p. 78-84, jan./mar. 1959.

Recebido em: 27 mar. 2012

Aceito em: 27 set. 2012 